\title{
The Role of Public Administration Encapsulating Public Policy Making and Implementation in Ghana
}

\author{
Aphu Elvis Selase \\ College of Public Administration, Huazhong University of Science and Technology, Wuhan, China
}

Email address:

elvis.qapito@yahoo.com

To cite this article:

Aphu Elvis Selase. The Role of Public Administration Encapsulating Public Policy Making and Implementation in Ghana. Journal of Public Policy and Administration. Vol. 2, No. 2, 2018, pp. 11-19. doi: 10.11648/j.jppa.20180202.11

Received: July 26, 2018; Accepted: October 5, 2018; Published: November 10, 2018

\begin{abstract}
This paper was aimed to highlight on the Ghana Public Administrative relevant tasks, the extent to their level of involvement, and the ways they influence through their participation thereby leading to the effectiveness and efficiency encompassing Ghana public policy implementation. The study mapped its investigation on empirical literature review that principally focused on the processes, actors, context of participation, among others. The analysis of the role(s) the public administration of Ghana plays, as a democratic state was drawn paying attention to the three variables such us Process, Actors or Stakeholders, and context in addition to outcomes. Mapping the performance of participatory episodes in terms of process, actors, and context as well as outcomes makes Ghana Public Administration possible to understand the multiple dimensions of knowledge, beliefs, and power, as well as meaning and values that they frame the public policy making and implementation in Ghana. Recommendations were enumerated at the end of the study encompassing transparency and accountability so as to avail the vacuum for policies to be participatory and inclusive in Ghana Modern Administration.
\end{abstract}

Keywords: Actions, Administration, Ghana, Implementation, Modern, Public, Public Policy, Policies, Role, Variables

\section{Introduction}

From 1990 on, public policy analysis has progressively been introduced into the field of Africanism. ${ }^{1}$ Public policies has, since 1990 thanks to the commitment of democratic transitions, [1] and the correlative topicality related to the problem of capacity building of the African State, ${ }^{2}$ a progressive entry into Africanism marked by borrowing from Anglo-Saxon policy analysis, [2], and the French School of

1 Maurice Enguéléguélé, 2002, "The analysis of public policies in the countries of sub-Saharan Africa. The contributions of the notion of reference and the concept of mediation ", in Political Africa, Paris, Karthala, p. 233-253; Dominique Darbon, 2004, "Can we re-read politics in Africa via public policies? In Alessandro Triulzi and Maria Cristina Ercolessi (eds.), State Power and New Political Actors in Postcolonial Africa, Milan, Feltrinelli.

2 .See, among others, the 2001 delivery of Africa political dedicated to "Reforms of African States", Paris, Karthala Study Center of Black Africa, 285 p. ; Dominique Darbon, 2003, "Reforming or reforming the projected administrations of Africa? "French Review of Public Administration, pp. 105-106, p. 135-152; Jeffrey Herbst, 2000, State and Power in Africa. Comparative Lessons in Authority and Control, Princeton, Princeton University Press; Dele Olowu, 2002, "Introduction. New Public Management: An African Reform Paradigm? Africa Development, vol. XXVII, Nos. 3-4, p. 1-16, Special Issue "State Needs", African Policy, 1996, No. 61.
Public Policy. ${ }^{3}$ The empirical studies multiply, the spaces of theoretical confrontation [colloquia, days of study, disputacio epistolary] know a rise in strength; the demand for consultancy from donors or the public authorities accentuates the phenomenon. Ghana, a West African country has also embrace prior in late 1990s public policy analysis and implementation but the most part experienced successions of military rule where only the governing elite made public policies. [3]. The author can cite among the examples as (1) the Constitution of 1960 was drawn and promulgated exclusively under elitist manner, [4, 5]. (2) The "Union Government" concept an amalgam of military and civilian appointed government which was proposed by the military government of General Acheampong through a non-consultative process, [6, 4]. (3) The Economic Recovery Program [ERP] which was formulated under Flt. Lt. Jerry John Rawlings' military regime and conducted in a non-participatory fashion, [7].

\footnotetext{
3 See, for example: Jean-Claude Thoenig, 1985, "Public Policies", in Traité de science politique, eds. by Madeleine Grawitz and Jean Leca, volume IV, Paris, Presses universitaires de France; Yves Meny and Jean-Claude Thoenig, 1989, Public Policies, Paris, Presses Universitaires de France.
} 
These examples mentioned above occurred not only in Ghana, but in most African countries which were independent in the 1960s. Without going back on the normativity aperies and the theoretical conservatism generally irrigating critics and crisis, its being admitted in public action which was engaged there at a moment where it was necessary to answer and to position itself in relation to a triple challenge [8] : the occurrence in political Africanism of the unresolved question of the nature of the African state, [9, 10]; the crisis of these states $[11,12,13]$, its redistributive and regulatory capacities, the renewal of its elites, the legitimacy of its leaders, the control of its territory; the need to finally reflect on the internal conditions of development and good practices that can improve performance in the fight against poverty. [14-16].

Ghana in the last two decades, became a young African country leading in a good public policy implementation with stable constitutional democracy. Ghana constitutional rule arguably democratizes the public policy-making process by guaranteeing the participation of all stakeholders in all the processes of development, [3].

The present paper aimed to analyze the role of the Ghanaian modern public administration role in public policy making and its implementation. The study was mapped on the review of empirical literature case studies.

\section{Overview of Public Administration}

In its original analysis, the term administration comes from a Latin word administrare, which means to serve, or to attend to someone's needs. Additionally and to qualify it, public refers to something that has to do with general, common and national interest [17].

The concept of Public Administration provides some background which encompasses administration and the public. The two terms administration and people become the cornerstone in the field of Public Administration. The critical phase of public administration is to grow and develop into a cooperative approach between the administrative institutions and the public. This cooperative approach in public administration is usually defined and based on a common vision. As [18] argues that public administration is 'one phase or aspect of human cooperation'. From [17] analysis of public administration, it could be deduced that public administration puts an obligation on the official to serve the public. Hence, a bureaucrat within a department or public agency is obliged to discharging his or her responsibilities in ensuring that services are provided to the society. Thus, public administration serves the public and is part of or is related to government. [19], in their analysis of the term public administration provide a general application of the term public to function of administration means that administration is not concealed, it is open to all, it is the opposite of the private administration and affects society. Contextually, the above notion by the two authors imply that the public-administration relationship is brought about by the fact that the public in practice has to do with the delivering of services to people through the performance of administrative functions. Therefore, the output-outcome model as a result of the practical functioning of public administration is necessitated by administrators in their relationship, with accountability to the citizenry.

Humans as we are, we are behavioral animals and so, individuals ought to undergo a constant scrutiny in as much as recruitment and selection process are not frowned upon in seeking for the best candidates for catapulting an organizational performance and effectiveness. [20] This therefore implies that, once the issue of public administration is mentioned, the focus is on people and their responsibilities as humans where they can change at any given point in time in as much as discharging their duties are concern.

The public and public administration are inseparable, especially in dealing with matters of governance, like accountability, responsibility, transparency and the rule of law. Against this background, public administration, both in theory and in practice, has to be discussed so that public administration's role is understood, as well as practices in public organization, public service in particular. Public Administration is broad-ranging and has a combination of theories and practices designed to promote an understanding of government and its relationship with the society. It also has to encourage the formulation of public policies to be more responsive to social needs and institute managerial practices on the part of the public organizations that are substantially attuned to effectiveness, efficiency, and increasingly, the deeper human requisites of the citizenry, [21]. Different authors within different contexts constantly raise the theory versus practice relationship. Within this context, the theory-practice relationship in particular, there is an indication of the importance of theory as one of the components within the Public Administration discourse. However, what is most essential is the fact that public administration is not an end in itself because theory plays a very important role in building and nurturing Public Administration and provides a basis to apply in practice. In their comment and analysis of public administration, [22] define public administration as that 'system of structures and processes', operating within a particular society as environment with the objective of facilitating the formulation of appropriate governmental policy, and the efficient execution of the formulated policy.

From this perspective, public administration establishes a bond between the society, public policy and government as key players by using structures and processes accurately. Therefore, public administration without people's involvement in public policy formulation and implementation, and the government's use of its structures and processes, is a fallacy. Public administration is influenced by external conditions and also influences societies by solving present and future problems. Additionally, public administration is determined by both objective societal elements, and the subjectivity of public administrators, [23]. In practice, it is stated that interest groups and other external forces could influence public administration. As a result, public administrators themselves become influential both in policy 
making and in institutional changes. In their analysis of scope and meaning of public administration, [24, 25] comment that wherever people associate for common purposes, the problem of administration presents itself. The authors further comment that the execution of agreed policies is a necessary responsibility of all institutional activities. In this context, public administration is not exempted from association for a common purpose. Furthermore, it takes a joint effort to deliver services to people under a government mandate. Public administration involves the coordination of all organized activities, having as its purpose the implementation of public policy. The coordination of organized activity is common to all administrative endeavors into private and public, and the implementation of public policy as key factors within this understanding of public administration. Human cooperation and joint effort are seen as critical in implementing government policies in particular, [26]. In this context public administration should be geared towards serving the public by implementing public policies through an organized and skilful administrative arm. Most importantly, is the fact that the implementation of public policy for service delivery purposes should be a joint effort between the public and the government? [27] define public administration as the management of men and women and materials in the accomplishment of the goals of the state. With reference to [27], public administration should make sure that the goals of the state are accomplished through the provision of services to people. However, the provision of services is the ability of management to apply public service prescriptions efficiently and correctly. [27]

Additionally, to make sure that public administration achieves governmental goals, elements of good governance must be in place, such as accountability, transparency, responsibility and the rule of law. [28] believes that, in some cases, public administration is used synonymously with public policy, public service and government administration. His analysis of public administration as opposed to public policy could be based on the fact that public administration in practice is entrenched within public policy formulation and its management, structuring and policy interventions by the restructuring of the public service in order to deliver services efficiently and effectively to the public.

Additionally, public administration ensures that government structures are structured properly and according to the legal framework to obtain and maintain good governance. [29] in his analysis, argue that public administration is very much a constitutional activity. This confirms that a constitution becomes critical in ensuring that government systems and organs of state function properly in order to ensure that governance is supported by strong and skilful managers. Therefore, public administration within a multidimensional approach, seeks to ensure that the roles of the state and government are fulfilled. It is also essential that a government and its citizenry respect and abide by its constitution.

Referring to Ghana as constitutional government where the Constitution is the supreme law of the Republic. The 1992
Constitution of Ghana was approved at the Referendum held on April 28, 1992 and promulgated by the Constitution of the Fourth Republic of Ghana Promulgation Law, 1992. It was last amended in 1996 by the Constitution of the Republic of Ghana [Amendment] Act, 1996. In this context, government officials have to ensure that the ethos and values (ethics, economic and efficient use of government resources and developmental public administration) of public administration crafted in that Constitution are upheld, such as the socioeconomic lives of people like housing, land, education and health are also upheld. At the same time, the public must be respected.

The concept of the supremacy of the law was an important change because it insisted that the law binds both the rulers and the ruled, [30]. Regarding to [30] argument, the government and the public servants, should serve the public with dignity and respect. The Constitution requires that government should deliver socioeconomic services to people and people are also expected to act according to the Constitution in demanding such services. In this context the ruled and the ruler have to respect the Constitution in order for public administration to function properly. The managers and other public servants in government shall respect and adhere to the provisions of the Constitution and other legal measures leading to the government Capacity building and improve public sector performance.

The policy-process approach is not "culture bound." It can readily be used to study policymaking in foreign political systems. It also lends itself to manageable comparisons, such as how problems reach governmental agendas, or how policies are adopted in various countries. Hence, the universal diverse perspectives cum as an academic discipline, encompassing public policy making. [31]

\section{Analyses of Ghana's Public Administrative Action}

The best illustration of the shift made by the analysis of public action in Ghana is that it reinforces the overcoming of the conception of the country as an enterprise of domination characterized by its efforts to impose a global political order, by replacing it with a perspective focused on its outcomes, that is, its ability and efficacy to solve problems in a changing environment in which the dilemma for the government is to be simultaneously (1) responsive such as aware of problems as well as expectations which often contradictory with the populations and their international partners., (2) accountable: government should be able to account for their action, which supposes that they know what they are doing and what are the results and (3) problem-solving: they must be able to produce or co-produce effective solutions [32].

Ghana national constitution of 1992 and Public Administration are totally democratized which lead democratizes the public policy making process by guaranteeing the participation of all stakeholders in all the 
processes of development.

To be aware of all the stakeholders in Public Policies making process, implementation and its importance in Ghana during the past decade, many major national events were organized to promote and sensitize public engagement in policy making with a long vision of the development of Ghana by 2020 "Ghana Vision 2020 that promised to upgrade the country to a middle income status by 2020 . The National Economic Forum and National Economic Dialogue was headed to determine the direction of the economy, and Ghana Poverty Reduction Strategies I and II to fashion out ways to reduce poverty, as well as the Structural Adjustment Participatory Review Initiative to assess ways to mitigate the social impact of structural reforms, [33, 7].

Therefore, it is not enough to know that opportunities for participation are now being made available in Ghana. The more interesting thing to know is the role of Public Administration that have been analyzed above and the genuineness and effectiveness of participation. The genuineness and effectiveness are indicators that measured by the extent of quality and legitimacy, as well as the impact of participation.

These indicators of measurement on the participation including depth, quality and legitimacy as well as impact raise important questions about participatory initiatives in Ghana: (1) who can participate and to what extent can they participate in policy making? (2) What participatory techniques or tools are employed? (3) What are the skills, competence and expertise levels of participants? (4) Do participants feel that their input is taken and their contributions shape policy decisions? (5) What are the challenges to meaningful citizen participation in policy making in Ghana and how can they be resolved? The Public Administration should seek the answers of these questions because public participation in representative democracies is meant to supplement, not replace, representative governance, [34] Therefore, the population do not have authority over policy decisions and essentially perform an advisory role with the exception of binding referendums, which is often an exceptional case and rarely employed in Ghana. As a democratic tool, citizens' participation is therefore a contradictory process. On one hand the state encourages citizens to get engaged. On the other, it leaves them dependent on government officials for access, information and action, [35]. The problem of participation is not so much the numbers of persons reached, but the quality of the deliberations they brink into and the credibility of the consultations. The quality of the discussions is determined both by the diversity and knowledge of the participants as well as information parity.

Accordingly, in assessing participation, it is important to critically examine both process and outcome. Process should refer to citizens having a clear opportunity to provide space for their input, the participatory tools used and the information made available as well as the feedback provided. The outcome means the end result new or revised policies that reflect, to some degree, citizens' input. In this paper the quality of participation and the influence of stakeholders on policy decisions are the core areas of analysis for which participation might meant. Ghana Public administration giving the positioning of citizens involvement as an addendum to representative governance, authentic or meaningful participation is important and leading to a good policy making and governance in Ghana. Such participation occurs when the potential exists that citizens involvement will shape policy decisions, which requires that appointed and elected officials should sincerely factor citizens input into policy analysis and decision-making, [35].

Policies Making Process in Ghana Modern Public Administration

Several studies had been undertaken to analyze the policy implementation process in Ghana among them, [36] in his study through the analysis of two cases (Ghana Poverty Reduction Strategy I and Growth and Poverty Reduction Strategy II) conclude that although a gradual shift to participatory decision making has occurred and improved policy processes and outcomes, it is bedeviled by several structural challenges that place premium on elite preferences to the neglect of those of unorganized and marginalized rural folk. This finding leaves important question marks surrounding some of the fundamental principles of the good governance mantra. Another study carried out by [3] framed on the two cases: the Re-view of the 1992 Constitution and the Reform to the Social Security System argued that the consensual approach to policy making in Ghana has emerged since the country return to democratic rule in 1993. This paradigm shift has improved the design and implementation of public policies and programs in Ghana. The author also added that the situation is far from satisfactory because marginalized and unorganized groups still suffer alienation; official actors still have a stronger urge over non authoritative players in participatory episodes; and elected and appointed participants still have informational advantage over their non-state counterparts. [37] compare the Ghana modern Public Administration with the "one party and military regime periods (1957-1992)" which was characterized by the policy making setting in Ghana in this period as a "closed circuit network" of politicians and senior bureaucrats with technical assistance sought from multilateral and bilateral donors. And concluded that Ghana Current Public Administration dealing with an effectiveness of public policies implementation process with the participation and consideration of all stakeholder view points and comments. [37] added that the exclusion of the domestic non-authoritative actors was blamed on the nature of the political environment at that time.

Many researches carried out in Ghana modern Public Administration using "the one party and military regime periods (1957-1992)" as a reference material concluded that the succession of military regimes began in 1966 did not tolerate dissent or public discussion on governmental decisions. [37]. Public opinion was seen not as a resource, but rather as a source of potential problems to be avoided or on occasions to be neutralized for political expediency, [38]. The short-lived democratic governments installed for the period 1969-1972 and again in 1979-1981 were either unable or 
unwilling to open up the political space that permitted citizen engagement in public affairs, [38] All these researchers had approved Ghana modern Public Administration efficiency and effectiveness and the role played in public policy making while criticized the "one party and military regime periods 1957-1992". The theorists propose and sketch some of the various issues relating to bureaucracy and phenomena in public administration such as management and leadership, governance, decision-making, political and administrative interface, ethics and administrative responsibility.

It is also important to understand public administration and its meaning properly, as well as its boundaries, because public administration, through its nature, is different from private or business administration. Against this background, public administration, both in theory and in practice, has to be discussed so that public administration's role is understood, as well as practices in public organization, public service in particular.

Public Administration is broad-ranging and has a combination of theories and practices designed to promote an understanding of government and its relationship with the society. It also has to encourage the formulation of public policies to be more responsive to social needs and institute managerial practices on the part of the public organization that are substantially attuned to effectiveness, efficiency, and increasingly, the deeper human requisites of the citizenry, [11]. Different authors within different contexts constantly raise the theory versus practice relationship. Within this context, the theory-practice relationship in particular, there is an indication of the importance of theory as one of the components within the Public Administration discourse. However, what is most essential is the fact that public administration is not an end in itself because theory plays a very important role in building and nurturing Public Administration and provides a basis to apply in practice. To add to, [39] 'the government sector should be clearly distinguished from the rest of the economy, where policy and management roles within government should be well defined. There should be a clear legal and administrative framework for fiscal management'.

In their comment and analysis of public administration, [22] define public administration as that 'system of structures and processes', operating within a particular society as environment with the objective of facilitating the formulation of appropriate governmental policy, and the efficient execution of the formulated policy. From this perspective, public administration establishes a bond between the society, public policy and government as key players by using structures and processes accurately. Therefore, public administration without people's involvement in public policy formulation and implementation, and the government's use of its structures and processes, is a fallacy.

Public administration is influenced by external conditions and also influences societies by solving present and future problems. Additionally, public administration is determined by both objective societal elements, and the subjectivity of public administrators, [23]. In practice, it is stated that interest groups and other external forces could influence public administration. As a result public administrators themselves become influential both in policy making and in institutional changes. "Policy Implementation can be defined as the stage where government executes an adopted policy as specified by the legislation or policy action. At this stage, various government agencies and departments, responsible for the respective area of policy, are formally made responsible for implementation." [40]

The goal of public policy cannot entirely be separated from its source. Both government and public policy help meet basic societal needs and obligations; decide how communities, states or nations manage resources; and keep general order in society. Implementation research objectives can be described as both analytical [reconstruction of the implementation process and the study of efficacy] as well as prescriptive [stating the conditions to ensure the success of policies]. According to the theoretical approach known as 'Top-Down', implementation presupposes the existence of an earlier stage; in which general decisions and objectives have been created, which are then actuated precisely through the implementation process. It would therefore be useful to evaluate the possible gap that exists between initial objectives and eventual results achieved, which would elucidate some of the challenges faced by policy makers in implementing policy. A closer examination of this approach reveals the conditions which policymakers rely on to ensure that objectives are achieved: the ease with which problems can be solved, the policy's ability to structure its own implementation, as well as external variables such as consensus and socioeconomic conditions. In reality, these preconditions are rarely present and therefore there are always a number of challenges in implementation of public policy.

Policy-making process is ongoing, messy and generally without a definitive beginning or end, political science, [41]. However, Ghana Public implementation involved in the process do tend to follow a general procedure, broken down into six phases as follows:

Phase 1: Public Policy Agenda Setting in Ghana Context

As the first phase in the cycle, agenda setting helps Ghana Public Administration who play the role as policy makers to decide which problems to address. Suggested topics for discussion go through several types of agendas before these individuals may move them forward. Amongst the agendas are included:

Systemic Agendas. Systemic agendas comprise all issues policy makers deem both worthy of note and in their realm of authority to address.

Institutional Agendas. These agendas are formed from the content of systemic agendas. Here, policy makers analyze problems and their proposed solutions in a strict amount of time.

Discretionary Agendas. These agendas address problems chosen by legislators that have not necessarily made it into the agendas mentioned above.

Decision Agendas. Decision agendas are the finalized list of issues to be moved to the next phase of the policy-making 
cycle.

Phase 2: Public Policy Formation in Ghana Context

In Ghana Public policy formation, solutions to problems are shaped and argued. This phase is characterized by intense negotiation between parties. Leaders, bureaus and other factions must fight for their own needs and desires, often in opposition to one another. Concerns might include budgetary issues, personal or political constraints, or the protection of certain existing programs. Ghana Public policies are therefore formed far more by the act of bargaining than by any other means. Policy formation continues even after initial legislation is passed, arising whenever amendments are suggested or the original legislation is reauthorized.

Phase 3: Public Policy Legitimation in Ghana Context

"Legitimacy" means that the public considers the government's actions to be legal and authoritative. To gain legitimacy in Ghana, a Public Policy must be moved through the legislative process. Once this happens, it is considered the law of the land and can be implemented as such. It must be mentioned that the legitimacy of a policy is only as good as the willingness of citizens to accept it. Therefore, it is possible for people to reject a policy if they view the policy makers' behavior or the legislation itself as unacceptable in some way(s).

Phase 4: Public Policy Implementation in Ghana Context

This phase puts Ghana Public Policies into action. Responsibility passes from policy makers to policy implementer, and the policies themselves may again develop further while this happens. Whether a policy succeeds can often be traced back to this phase; a well-written policy with a poor implementation can end in failure.

Phase 5: Public Policy Evaluation in Ghana Context

Often Ghana Policy makers conduct evaluations to determine if the policies they create are effective in achieving their goals. When determining this, they used to answer the following questions which are applied in the context of the specific Public Policy accordingly:

How to evaluate outcomes effectively

How to measure the outcomes

How to navigate between the efficiency of a policy and its effectiveness (the former is often easier to measure than the latter).

Evaluation may occur either during implementation or after the policy in question is finished.

Phase 6: Public Policy Maintenance, Succession or Termination in Ghana Context

Once implemented, Public Policies in Ghana are periodically gauged for their relevancy and use. This may result in their continuation, amendment or termination. These incidents often occur due to policy makers' shifting goals, values, beliefs or priorities. An example of Ghana Poverty alleviation Public Policy "Medium-Term Development Policy Framework, Ghana Shared Growth and Development Agenda [GSGDA, 2010-2013]" has been amended to Medium-Term Development Policy Framework, Ghana Shared Growth and Development Agenda [GSGDA, 2014-2017]"

When new issues arise, the policy-making cycle begins again, helping governing bodies successfully address new and important challenges.

Table 1. Some Public Policies of Ghana

\begin{tabular}{|c|c|c|}
\hline Policy & Start date & End date \\
\hline Health Sector Medium Term Development Plan 2014-2017 & 2014 & 2017 \\
\hline National Nutrition Policy & 2014 & 2017 \\
\hline Strategy for the Management, Prevention and Control of Chronic Non-Communicable Diseases in Ghana & 2012 & 2016 \\
\hline Health Sector Medium Term Plan & 2010 & 2013 \\
\hline Medium-Term Development Policy Framework, Ghana Shared Growth and Development Agenda (GSGDA, 2010-2013) & 2010 & 2013 \\
\hline Child Health Policy & 2007 & 2015 \\
\hline Infant and Young Child Feeding Strategy for Ghana & 2007 & --- \\
\hline National Health Policy Creating Wealth through Health & 2007 & 2011 \\
\hline Under Five's Child Health Policy: 2007 - 2015 & 2007 & 2012 \\
\hline Creating Wealth through Health & 2007 & 2015 \\
\hline Growth and Poverty Reduction Strategy (GPRSII) & 2006 & 2009 \\
\hline Imagine Ghana Free of Malnutrition & 2005 & --- \\
\hline Integrated Anaemia Control Strategy & 2003 & --- \\
\hline Labour Act & 2003 & --- \\
\hline National Reproductive Health Service Policy and Standards & 2003 & --- \\
\hline Breastfeeding Promotion Regulations 2000, LI1667 & 2000 & --- \\
\hline Vitamin A Policy & 1998 & --- \\
\hline Breastfeeding Promotion Regulations & 1995 & --- \\
\hline Food and Drug Law and Amendments: Universal Salt Iodisation & 1995 & --- \\
\hline National Plan of Action on Food and Nutrition & 1995 & 2000 \\
\hline Food and Agriculture Sector Development Policy & --- & --- \\
\hline Regenerative health and nutrition-program & --- & --- \\
\hline
\end{tabular}

Source: World Health Organization: Global database on the Implementation of Nutrition Action [GINA] 


\section{Dimensions of Administrative Responsibility in Ghana}

Ghana government Administrative responsibility applies both to the individual and a political system. Ghana is no exception, especially in its transformation into a solid democratic state in West Africa. [28] provides the following elements of administrative responsibility that have an ethical 'tone' and clarifies the role of public servants in a democratic state:

Authority: In a modern state, an individual administrator or departmental agency is authorized to act on behalf of the state. He strongly emphasizes that it would be ultra vires, for example, for one to sign documents he or she has not been authorized to do, or a government agency to undertake a programme unsanctioned by those competent to do so;

Accountability: Democratic accountability implies answer-ability to several levels of control as well as one's conscience. For example, public administrators are not only answerable to hierarchical superiors in the public service, or to political executives (ministers) to the legislature, but also to subordinates. They are also accountable to the public and answerable to the moral conscience; Administrative responsibility in a democratic state involves personal judgment or the discretion officials are allowed to exercise;

Neutrality: In public administration, neutrality is always a debatable concept because it is by definition a political action. Based on some connotations, neutrality means that officials should apply rules and regulations impartially when serving members of the public regardless of personal, ethnic, racial or any other considerations that have been explicitly declared irrelevant in a given democratic state. The ideal of neutrality emphasizes the essential aspect of public administration, namely that it involves the enabling actions required so that a public service could be rendered to the relevant individuals, community or society without discrimination, unless under politically determined circumstances, for example, preferential treatment of a historically disadvantaged group;

Openness: Open governance is associated with the notion of transparency. It promotes the feeling among society that the public service is not unduly secretive, that the true basis of democracy requires access to vital information on critical decisions, actions and inaction's of the public servants. For example, a member of the public wants to know from the public servants on what basis his or her application for a passport is delayed or denied or the existing one withdrawn; and;

Virtue: It is an ideal that public officials must have morals all the time. An offer of employment in the public service is regarded as a form of public trust requiring that officials be committed to principles, morally attuned, trustworthy, honest, dependable and reliable. Additionally, officials are expected to exhibit a high degree of moral integrity.

Challenges of Public Policies Implementation in Ghana

While Ghana has upgrade in democracy with a good political stability which lead to the smooth implementation of some policies such as those cited above, the country still suffering of some challenges occurring in public policies implementation. [3] while approving the greatness evolution of Ghana government policy implementation success added that, the situation is far from satisfactory because marginalized and unorganized groups still suffer alienation; official actors still have a stronger urge over non authoritative players in participatory episodes; and elected and appointed participants still have informational advantage over their non-state counterparts. Also, we can cited some major challenge in the National Health Insurance Scheme [NHIS] in Ghana include; the cooperation between the schemes and other health care service providers is haphazardly managed which causes the falsified declaration of bills to the National Health Insurance Authority making the overall health insurance bill unsustainable after several months of accumulation, [42].

Again, a poor administrative structure for career progression was also identified, [43]. That only half of highly educated health personnel received in-service training in 2003 , with the majority receiving only one training session. Most of the job descriptions are also too routine, breeding laziness and unnecessary conversations at the offices. As a result leading to a poor customer service even in the preparation of ID cards for subscribers. [42] study, delays in the renewal of ID cards were highlighted as some respondents complained of having to wait for six months for a renewal. This is a breach of the official policy of card renewal of two weeks, [42]. The study by [44] also concluded the following as some of the challenges that bedevil the implementation of the NHIS; among them: (1) Cash flow delays from the health insurance authority, (2) lack of capacity to procure essential drug and non-drug consumables, and (3) limited space within the hospitals to cope with the increasing number of service demands. [45] also outlined the following as other implementation problems of the NHIS such as (1) Poor leadership, (2) corruption, (3) lack of consensus, (4) rapidity and politicization of implementation, (5) lack of participation, (6) poor sense of direction, (7) limited understanding and management of the political challenges, and (8) weakened checks and balances and use of short cuts.

But some researchers while approving the effective efforts of Ghana Public Administration in Health policies implementation, regard the criticism of some research in Ghana health care policy implementation argued that the 'health policy' is an authoritative statements of intent, probably adopted by governments on behalf of the public, with the aim of altering for better the health and welfare of the population, [46]. Health policies are not easy to implement even in developed countries, hence Ghana's National Health Insurance Scheme is a huge development step taken. Countries which have achieved universal coverage are wealthier nations of Western Europe, Canada, Japan and South Korea. They have done so over the long rather than short term. The structure of Ghana's economy, 
with many citizens employed in the non-formal sector and living in rural communities and small towns with poor road networks coupled with little access to telecommunication posed a major challenge to the universal health delivery in the country, [45].

\section{Conclusion cum Recommendations}

In the nutshell, looking at the role played by Public Administration in Ghana, it is realized that, the modern government administrative responsibility as summarized are as follows:

Bureaucracy in Ghana is as a corps of appointed officials with the very core of constitutional democracy in the sense that modern government cannot operate or maintain service delivery without an efficient administrative organization;

Ghana Public administration's role in public policy making is not a question of either democracy or bureaucracy, or of their constitutionalism or efficient administration but a combination of the two, a working balance between them, in short it is a question of a responsible bureaucracy;

Ghana Public administration has set an administrative agency competent in each specific field which being responsible for formulating as well as executing public policy; and

Ghana Administrative hierarchies have a profound influence on policy formulation, especially on the exercise of the discretionary powers allowed in everyday operations and the processing and developing of specific proposals for legislative consideration.

With reference to the above authors, it is important to note that administrative responsibility is crucial because it calls for an efficient and effectiveness in public policy implementation.

In line with the author's remarks and conclusion, Ghana modern public administration had learnt from the public policy implementation faille in the military rule where only the governing elite made public policies. The modern Public administration in Ghana are aware that in the long run a policy that does not have support of the people will never survive and be brought to the political agenda. Ghana Public Administrative influence through their participation into Ghana public policy implementation that leading to the effectiveness and efficiency. Transparency and accountability to a large extent, be ensured by making policies participatory and inclusive in Ghana Modern Administration.

\section{References}

[1] Nicolas and Philippe Sc. [2013], "Grounding with the People: Participatory Policy Making in the Context of Constitution review in Ghana" in Journal of Politics and Law, Vol. 6, No.1, pp. 99-110.

[2] Douglas E. Ashford (dir.), 1978, Comparing Public Policies. New Concepts and Methods, Beverly Hills, Sage; Wayne Parsons,

[3] Abdulai M. [2015], Ghana's policy making: from elitism and exclusion to participation and inclusion? International Public
Management Review Vol. 16, Issue. 1, 2015 www. ipmr. net.

[4] IDEG (Institute for Democratic Governance) [2007], Ghana, Democracy and Political Participation: A Review. Open Society Initiative of West Africa, Johannesburg.

[5] Gyimah B. 2010, International Public Management Review Vol. 16, Issue. 1, 2015 www. ipmr. net.

[6] Frempong, K. D. [2007], Constitution-making and Constitutional Rule in Ghana, Paper presented at the Ghana Golden Jubilee Colloquium, University of Ghana, 1-2 March.

[7] Vordzogbe, S. D. and Caiquo, B. and. [2001], Report on Status Review of National Strategies for Sustainable Development in Ghana, IIED, London.

[8] Maurice E., [2002], "The analysis of public policies in the countries of sub-Saharan Africa. The contributions of the notion of reference and the concept of mediation ", in Political Africa, Paris, Karthala, p. 233-253.

[9] Jean M., [1991], Black African States. Training, mechanisms and crises, Paris.

[10] Aphu E. S, 2018. Advances in Social Sciences Research Journal-Vol.5, No.5.

[11] Jean-François B., Stephen E. and Beatrice H., [1997], The Criminalization of the State in Africa, Brussels, Complex, "International Space" collection.

[12] Jean B., [1989], The State in Africa. The politics of the belly, Paris, Fayard;

[13] Luc S. [2002], The State elsewhere: between hard core and empty box, Paris, Economica.

[14] Claude T., [1996], Les politiques publiques, dans Traité de science politique, sous la dir. de Madeleine Grawitz.

[15] Goran H., [1999], "Rethinking the Study of African Politics", in Governance and Democratization in West Africa, eds.

[16] Oluwu D., Adebayo W. and Kayode S., [2004] Council for the Development of Social Science Research in Africa, Dakar, p. 9 ff. ; Léonora Angeles, "New Issues, New Perspectives: Implications for International Development Studies," Canadian Journal of Development Studies, Vol. 25, No. 1 .

[17] Lungu, G. F. [1997]. Public Administration notes. Bellville: University of the Western Cape.

[18] Waldo, D. [1968]. "Scope of the Theory of Public Administration." In Charlesworth.

[19] Hanekom and Thornhill [1983], Public administration in contemporary society: a South African perspective, National Libraries of Australia.

[20] Aphu E. S, 2018. Journal of Public Administration and Governance ISSN 2161-7104 2018, Vol. 8, No. 3.

[21] Coetzee [1988], Public administration - a South African introductory perspective.

[22] Fox, W; Schwella, E. \& Wissink, H. 1991. Public Management. Kenwyn, Cape Town: Juta and Co

[23] Jun, J. S. 1986. Public administration: Design and problem solving. New York: Macmillan Publishing Company. 
[24] Gaus, J. M. [1936]. American society and public administration. In J. M. Gaus, L. D. White, \& M. E. Dimock (Eds.), The frontiers of public administration. Chicago: University of Illinois Press.

[25] Dimock, M. E. [1937]. Modern politics and administration New York: American Book Company. Google Scholar.

[26] Gortner, H., [1981] Administration in the public sector Harold F. Gortner. National Libraries Australia.

[27] Shafritz and Hyde [1992], Classics of Public Administration (Brooks/Cole series in public administration) ISBN: 9780534173104

[28] Lungu, G. F. [1997]. Towards a redefinition of administrative responsibility in a democratic South Africa: Inaugural Lecture. Bellville: University of the Western Cape.

[29] Yehezkel Dror, [1989], Public Policymaking Reexamined, New Brunswick: Transaction Publisher, pp. 132-141.

[30] Perry, J. L. [1989]. Making policy by trial and error: merit pay in the federal service. Policy Studies Journal, 17 (2), 389-405.

[31] Aphu E. S, et al, [2015] Public Finance and the Responsible Factors Coupled with Public Expenditure: Ghana as the Focus. Journal of Economics and Sustainable Development. ISSN 2222-1700, ISSN 2222-2855. Vol.6, No.20.

[32] Gerard W., [2000], Inequalities and Public Policies in Africa Plurality of standards and acting, Paris, Karthala, Research Institute for Development.

[33] Aphu E. S, International Journal of Recent Advances in Multidisciplinary Research Vol. 05, Issue 05, pp.3830-3834, May, 2018

[34] Phillips S. and Orsini M. [2002] Mapping the Links: Citizen Involvement in Policy Processes, Canadian Policy Research Networks Inc.

[35] Woodford M. and Preston S. [2011]. Strengthening Citizen Participation in Public Policy-Making: A Canadian Perspective.
[36] Abdulai M. [2013] ivic Engagement in Public Policy Making: Fad or Reality in Ghana? Journal of Politics and Policy

[37] Ohemeng F. [2005], Civil Society and Policy Making in Developing Countries: Assessing the Impact of Think Tanks on Policy Outcomes in Ghana. Journal of Asian and African Study.

[38] Amoako T. and Bartholemew A., [2008] Poverty reduction in action: Perspective and lesson from Ghana.

[39] Aphu E. S, \& Smile P. G, [2015] International Journal of Engineering, Management \& Sciences (IJEMS) ISSN-23483733, Volume-2, Issue-6, Public Policy Making Issues in the Perspectives of Universal and Academic Discipline.

[40] Theodoulou, Stella Z. and Chris K. [2004]. The Art of the Game: Understanding Policy Making. Thomson Wadsworth.

[41] Susan B. [Island Press, 1998]. Understanding environmental administration and law provides an engaging, introductory overview of environmental policy 3rd edition.

[42] Wahab, H. [2008]. "Universal healthcare coverage: assessing the implementation of Ghana's NHIS Law. Paper Prepared for the Workshop in Political Theory and Policy Analysis Mini Conference, Indiana University, Bloomington, April 26-28.

[43] Agyepong, I. A, Bruce, E. S., \&Narh-Bana, S. [2006]. Making Health Insurance Equitable and Pro-Poor Financing Mechanism in Ghana: Some Reflections. Ghana: Medical Education Resources Africa [MERA].

[44] Sakyi, E. K., AtingaF. A., \& Adzei M. [2012]. Managerial Problems of Hospitals under Ghana's National Health Insurance Scheme.

[45] Agyepong and Adjei. [2007], "Socio-Economic Transformation in Ghana: Comparative Analysis of Approaches to Development in the Nkrumah and Rawlings Years" in Research Review, Vol. 27, Issue 1.

[46] Lee, K., \& Mills, A. [1982] "Policy Making and Planning in the Health Sector". London and Sydney: Croom Helm. 